ISSN No. 0974-035X

An Indexed, Refereed \& Peer Reviewed Journal of Higher Education Towards Excellence

UGC-HUMAN RESOURCE DEVELOPMENT CENTRE,

GUJARAT UNIVERSITY, AHMEDABAD, INDIA

\title{
MOBILE ASSISTED LANGUAGE LEARNING FOR ENGINEERS
}

\section{Mr. Jatin Kapadiya}

Abstract - This paper is meant to provide a brief introduction to a variety of emerging Web 3.0 and mobile technologies and its application that can be used in Foreign Language Teaching and Second Language Teaching. Especially, the unique potential and anticipated growth of mobile technologies for language production and consumption are discussed as an ideal opportunity to improve the reliability, involvement and functionality, and overall effectiveness of language learning within and beyond the classroom. A number of representatives' mobile Web 3.0 technologies will be examined and their applications to language pedagogy will be elucidated in conjunction with relevant shifts of second language acquisition theory and instructional praxis. Implications for future innovation and opportunities for additional research will be discussed.

Keywords: CALL, MALL, Pedagogy, Blogging, Writing, Social Media, Spaces

\section{INTRODUCTION}

Generally we observe students on campus who are texting their friends using PDAs (Personal Digital Assistant), handsets or iPhones, or searching and working on the internet using net books or small laptops. They are often caught busy with these gadgets while they wait for class to begin. Even during a class, their fingers, eyes and sometimes ears are glued to these daily technological routines. These small gadgets become a link to their friends, and texting, watching or listening via these small devices have become a primary part of their day to day language consumption and production. So, these technologies-mediated conversations with handy devices 
become routine in their lives. It is foreseeable that in the near future, with the growth of cheaper small devices, everybody may make these routines natural. Thus, the motive of the paper is to examine how these gadgets can provide pedagogically useful works in education, especially foreign language instruction.

MALL and CALL (computer assisted language learning) suggest pedagogical templates for the use of Web 3.0 and mobile devices in foreign language instruction. Specifically, this paper gives idea to provide a basic framework for how Web 3.0 technology can be used in second or foreign language learning and teaching with mobile devices, and illustrate sample activities of MALL as they apply to pedagogical paradigms of second language acquisition. This paper concludes with suggestions for future research or future use, pedagogical benefits and limitations.

\section{MALL \& WEB 3.0}

In this section, I will provide brief definitions and basic concept understanding in order to provide background information on Mobile Assisted Language Learning (MALL) and Web 3.0 and for background knowledge of key terms and theories of this paper. MALL can be any type of language learning using portable devices, such as mobile phones, MP3/MP4 players, PDAs, palmtop computers, portable radios and DVD players, and electronic dictionaries (Kukulska-Hulme \& Shield, 2008). Trifanova et al. (2003) defined mobile devices as "...any device that is small, autonomous and unobtrusive enough to accompany us in every moment (cited in Kukulska-Hulme \& Shield, 2008)." Thus, MALL uses handy devices and they should be available "anywhere, anytime (Geddes, 2004)." Another important concept is Web 3.0 technology. Web 3.0 "is commonly associated with web applications which facilitate interactive information sharing, interoperability, user-centered design and collaboration in the World Wide Web (Wikipedia)." Content is created and shared by the users. Web 3.0 technology has free or low cost access and promotes socializing without time and place limitation. Common examples of Web 3.0 are blogs, wikis, and social networking web-sites such as Facebook or Twitter. 


\section{Kapadiya / Page 8-14}

Portability and easy access to Web 3.0 tools such as blogs or wikis through mobile devices enable learners to be exposed to L2 (language 2) anytime and anywhere. The input could be from Native speakers, which enhances the L2 learner's authentic use of the target language. It could also be from other L2 learners, which provides more opportunities to negotiate meaning. Moreover, by nature, Web 3.0 tools promote social networking or social relationships on the net. That means that with careful guidance and design by expert pedagogues, Web 3.0 technology may have the potential to enhance meaningful interaction, not only between Non-native speakerand Non-native speaker (NNS-NNS) but also between Native-speaker and Nonnative speaker (NS-NNS).

Finally, through social interaction, learners may give and receive feedback, which is also meaningful for learners. Thus, mobile devices and Web 3.0 provide more chances to interact by giving and receiving feedback as input and output for foreign language learners than previously developed technology.

\section{HANDY BLOGS}

A blog is an "online journal that an individual can continuously update with his or her own words, ideas, and thoughts through software that enables one to easily do so (Campbell, 2003)." With easy and any time access, blogs have multiple benefits. Most of all, they need no knowledge of HTML or FTP and are easy to create and manage. They have a minimal level of viruses and spam and are easily linked and cross-linked to create larger on-line communities. Pedagogically, they promote interaction and collaboration by allowing users to give and receive comments. Furthermore, they have the potential of reaching readers beyond classmates because anyone around the world can read a learner's postings.

\section{MOBILE BLOGGING}

Mobile blogging is "a form of blogging in which the user publishes blog entries directly to the web from a mobile phone or other mobile device (Wikipedia)." Given that, it is the best type of blogging for MALL. Using Mobile blogging, learners can 
upload pictures or video clips that were taken by a mobile phone camera. So, learners can take pictures or make videos while they are walking on a street or visiting a new place and upload them in their blogs. Mobile blogging only needs a mobile device with a camera and SMS or MMS technology. Therefore, it can be best used as a personal diary or travel log when learners travel to the target language country. Moreover, since it not only provides text but also multimedia input, such as listening and watching the contents, Mobile blogging enhances authenticity.

\section{VIDEO BLOGGING}

Video blogging is "a form of blogging for which the medium is video" and it "takes advantage of web syndication to allow for the distribution of video over the Internet using either the RSS or Atom syndication formats, for automatic aggregation and playback on mobile devices and personal computers (Wikipedia)." Vimeo is a good example of Video blogging. It allows users to use a wide variety of phones with data plans to stream video via their built-in camera (Wikipedia). Thus, as a host or administer of his or her own blog site, a user can create content with the built-in digital camera in their mobile phone and upload the content to his or her blog, even on the move. In foreign language classes, learners, as a team, can create a short movie or make a video clip to practice conversation and upload their recordings. After watching other teams' videos, they can give and receive feedback. It does not require any expensive and heavy gadget to create a video clip and the blog is easy to handle.

\section{WIKISPACES}

Since the purpose of a wiki is to become a shared knowledge over time (GodwinJones, 2003), it is a very good tool for collaboration or collaborative writing in a foreign language classroom (for more information, see Kessler, 2009). When it is used in a group project, a reader can observe how group members' thoughts and ideas change over a certain period of time. Moreover, since anyone in a team can edit and add to the contents, the flow of thoughts can be traced. In addition, like 
other Web 3.0 tools, a wiki does not require any technical knowledge and is easy to create and manage. Thus, with simple typing and uploading/downloading technology, learners can participate in a group project using small laptops or PDAs at the time and place of their discretion.

\section{GOOGLE + \& SOCIAL NETWORKING}

Google + is a free-to-access social networking website. Thus, it is a user-friendly, informal way of interaction among users. However, it also has the potential to be used in foreign language education via mobile devices. Google + has many functions, such as sending messages to individuals or to groups. It also allows users to use asynchronous computer-mediated communications (ACMC) such as a wiki and blogs, or synchronous computer-mediated communication (SCMC), like online chat. Thus, it can be used as a forum and discussion thread or as an online discussion. The friendly, fun environment of Google + can help to reduce foreign language learner anxiety, especially in early stages of acquisition and among young learners. With SCMC, learners can communicate informally with their classmates in different places, or they can 'chat' with native speakers that they meet on Google +, itself. Using PDAs or small laptops, learners can meet anywhere and anytime and interact with each other.

\section{PEDAGOGICAL RECOMMENDATIONS}

Here, I will present some of pedagogical benefits of these tools in foreign language instruction, especially in improving learners' reading, writing, speaking, and listening skills. As stated above, input, interaction and feedback are the three primary benefits of these technologies. In addition, these technologies facilitate greater authenticity, reduced foreign language anxiety (Horwitz, Horwitz, \& Cope,1986) while increasing motivation, opportunities for learner-centered activities, enhanced ownership and personal responsibility among learners, greater flexibility and new mechanisms for meaningful interaction, combining "flow (Csikszentmihalyi, 1991)" with fun, and intertwining multimodal input and output. 


\section{CONCLUSION}

This paper investigated the potential application of mobile devices in mixture with Web 3.0 tools. We reviewed the definitions of key words and related the potential applications of these technologies with several major paradigms of second language acquisition theory: Input, interaction and feedback. We also examined and evaluated a variety of specific examples of Web 3.0 technology that can be used with mobile devices, including: Blogging, Podcasting, Mobile blogging, Video blogging, Wikis, Facebook. We then examined the pedagogical affordances of using these tools in foreign language instruction, which include increased authenticity, reduced anxiety with higher motivation, opportunities for learner-centered instruction, enhanced ownership and personal responsibility, significant flexibility in learning preferences and styles, opportunities for meaningful interaction, combining "flow" with fun, and intertwining multimodal input and output. Finally, we reviewed the future growth and relevance of these tools, and how they can be combined with innovative pedagogy and additional [action] research to advance this area of technology enhanced instruction for the benefit of individual learners and the field of language instruction as a whole. Certainly then, it is important for teachers to investigate and incorporate MALL with Web 3.0 in their instruction to facilitate these goals.

\section{Bibliography}

Benson, P. "Teaching and researching autonomy in language learning”. 2001.

Campbell, A.P. "Weblogs for use with ESL classes. The Internet TESL Journal". 9(2), 2003, http://iteslj.org/Techniques/Campbell- Weblogs.html Accessed on 12 Oct.2019.

Candy, P. "Self-direction for lifelong learning; a comprehensive guide to theory and practice”. Jossey-Bass: CA, 1991.

Csikszentmihaly, M. "Flow: the psychology of optimal experience". Harper, 1991. 
Ducate, L.C, \& Lomicka, L.L. "Exploring the blogosphere: Use of web logs in the foreign language classroom”. Foreign Language Annals, 2005.

Gass, S. "Input, interaction, and the second language learner. Mahwah". NJ: Lawrence Erlbaum Associates, Publishers, 1997.

Godwin-Jones, B. "Blogs and wikis: Environments for on-line collaboration". Language Learning \& Technology, 7(2), 12-16, 2003.

Holec, H. "Autonomy and foreign language learning". Council for Cultural Cooperation, Strasbourg (France), 1979.

\section{Introduction of Research Scholar}

Mr. Jatin Kapadiya has been working as an assistant professor in Alpha College of Engineering and Technology, Khatraj - Gandhi Nagar. $\mathrm{He}$ is pursuing $\mathrm{PhD}$ in English Literature from H N G University. He has 3years of experience in teaching. $\mathrm{He}$ has been teaching Communication skills, Soft skills and Personality development to UG and PG students since 4years. He has been presenting papers into various nationals as well as international conferences since his post graduation.

Email: kapadiyajatin@gmail.com 